\title{
Gender Differences in Internet Addiction among University Students in the Slovak Republic
}

\author{
RIGELSKY, M. ${ }^{1}$, MEGYESIOVA, S. ${ }^{2}$, IVANKOVA, V. ${ }^{3}$, AL KHOURI, I. ${ }^{4}$, SEJVL, J. ${ }^{5}$
}

1 | University of Prešov, Faculty of Management, Department of Marketing and International Trade, Prešov, Slovak Republic

2 University of Economics in Bratislava, Faculty of Business Economics, Košice, Slovak Republic

3 | University of Prešov, Faculty of Management, Department of Economics and Economy, Prešov, Slovak Republic

4 | Shams Orthopaedic Clinic, Banská Bystrica, Slovak Republic

5 | Charles University, First Faculty of Medicine and General University Hospital in Prague, Department of Addictology, Prague, Czech Republic
Citation | Rigelsky, M., Megyesiova, S., Ivankova, V., Al Khouri, I., \& Sejvl, J. (2021). Gender differences in internet addiction among university students in the Slovak Republic. Adiktologie, 21(1), 35-42.

http://doi.org/10.35198/01-2021-001-0001
BACKGROUND: The internet is an integral part of today's life; therefore, the risk of internet addiction is very high. The current consequences of internet addiction are not comparable to those of other types of addiction. However, internet addiction may be a serious problem in the future. For this reason, this issue should be addressed today. AlMS: The primary objective of the study was to assess the differences in internet addiction between males and females in a sample of university students in the Slovak Republic. Differences were assessed in the total internet addiction score, as well as in the individual sub-scales of the Internet Addiction Test (IAT) (Salience, Excessive Use, Neglect Work, Anticipation, Lack of Control, Neglect Social Life). METHODS: A questionnaire survey was conducted in 2020. The objective of the study was mainly achieved using the non-parametric Mann-Whitney test. SAMPLE: The population was selected in the form of a non-random sample and consists of 1612 responses from students of Slovak universities. Data obtained using the standardized IAT scale was included in the analyses. RESULTS: The overall rate of internet addiction in the research sample was not critical, while increased scores were found in the Neglect Work, Anticipation, and Lack of Control sub-scales. Significant differences were identified in the areas of Salience, Excessive Use, Neglect Work, and Neglect Social Life. In general, male students showed a higher rate of internet addiction. CONCLUSIONS: Internet addiction in high-risk population groups should be systematically monitored. The lifestyle of university students may be a predictor of these addictions, which may be a serious problem in the future.

Keywords | Gender - Internet - Internet Addiction Test (IAT) - Non-Substance Addiction - Public Health - Health Perception - Questionnaire - University Students - Slovakia 


\section{INTRODUCTION AND THEORETICAL BACKGROUND}

Internet-related behavioural disorders are on the rise. In the field of addictology, public health policy focuses mainly on substance addictions, which are currently incomparably more destructive than non-substance addictions. However, this ratio may change with the development of technology and changes in work and private life.

The internet is not only a popular element of the present, but a ubiquitous part of people's lives. It is a place where users can find information and social contact, but also entertainment. The internet offers many benefits and opportunities, but also great threats and risks (Guan \& Subrahmanyam, 2009; Levy \& Strombeck, 2002; Vega-Almeida \& Arencibia, 2019). In society as a whole, the line between healthy and problematic internet use is shifting every day, with the social identity of the individual being emphasized (Travaglino et al., 2020). This is especially evident for adolescents and young people who push the limits (Ooi et al., 2020); and therefore, the prevention of uncontrollable and harmful internet use among young people seems to be crucial, which is considered to be a major challenge (Echeburua \& de Corral, 2010). University students are no exception and they are also considered a risk group, which is why many international studies dealing with problematic internet use and internet addiction focus on this population group (Chi et al., 2016; Christakis et al., 2011). The fact that university students are at risk is supported by the findings in the study conducted by Li et al. (2015), who found that the first perception of the problem of excessive internet use comes at an average age of 16, while US university students who have experienced excessive internet use also perceived its consequences, such as lack of sleep, academic underperformance, failure to exercise and to engage in personal social activities, negative affective states, and reduced ability to concentrate. In this population group, problematic internet use can be associated with many other dimensions of students' lives, such as lower learning satisfaction and poorer academic grades, but also depression, loneliness, and poorer physical health (Chen \& Peng, 2008). Additionally, Javaeed et al. (2020) revealed that internet addiction is negatively associated with the academic performance of university students. At the same time, Aznar-Diaz et al. (2020) confirmed a significant and positive correlation between internet addiction and academic procrastination. These facts underline the importance of examining the prevalence of internet addiction among students in different countries, as knowledge of the current situation can help address this issue, which could have serious consequences in the future.

Internet addiction is an impulse control disorder and can be explained as excessive or poorly controlled preoccupations, urges, or behaviours related to computer use and internet access that lead to impairment or distress (Shaw \& Black, 2008). This disorder can be properly detected using various diagnostic tools, one of which is the Internet Addiction Test (IAT). The IAT is a frequently used tool to reveal problematic internet use and internet addiction among people (Lu et al., 2020; Masi et al., 2020; Tsimtsiou et al., 2015). Many studies have shown its usefulness in diagnosing internet addiction among university students too (Chang \& Law, 2008). The author of this diagnostic tool, Young (2017), distinguishes six basic sub-scales on which the items of the questionnaire are based: (i) Salience, (ii) Excessive Use, (iii) Neglecting Work, (iv) Anticipation, (v) Lack of Control, and (vi) Neglecting Social Life. In her publication, the author describes these subscales as follows.

Salience. High scores for Salience-related items suggest that the respondent most probably feels preoccupied with the internet, hides his or her behaviour from others, and may display a loss of interest in other activities and/or relationships only to prefer more solitary time online. High scores also indicate that the respondent uses the internet as a form of mental escape from disturbing thoughts and may feel that life without the internet would be boring, empty, or joyless.

Excessive Use. High scores for Excessive Use-related items indicate that the respondent engages in excessive online behaviour and compulsive usage, and is intermittently unable to control his or her time online, which he or she hides from others. High scores also suggest that the respondent is very likely to become depressed, panicked, or angry if forced to go without the internet for an extended length of time.

Neglect Work. High scores for Neglect Work-related items suggest the respondent may view the internet as a necessary appliance akin to the television, microwave, or telephone. Job or school performance and productivity are most probably compromised as a result of the amount of time spent online and the respondent may become defensive or secretive about the time spent online.

Anticipation. High scores for Anticipation-related items indicate that the respondent most probably thinks about being online when not at the computer and feels compelled to use the internet when offline.

Lack of Control. High scores for Lack of Control-related items suggest that the respondent has trouble managing his or her online time, frequently stays online longer than intended, and others may complain about the amount of time he or she spends online.

Neglect Social Life. High scores for Neglect of Social Liferelated items indicate that the respondent most probably utilizes online relationships to cope with situational problems and/ or to reduce mental tension and stress. High scores also indicate that the respondent frequently forms new relationships with fellow-online users and uses the internet to establish social connections that may be missing in his or her life.

Omoyemiju and Popoola (2020) used the IAT in their study examining the prevalence of internet addiction among Nigerian students. The authors revealed that male students were more internet-addicted compared to their female counterparts. These findings are consistent with the findings revealed by Canan et al. (2012), who studied Turkish students, or Shao et al. (2018), who studied Chinese students. Young's diagnostic tool, the IAT, was used in a similar Chilean study, in 
which Berner et al. (2014) confirmed that internet addiction can be associated not only with depressive symptoms in students, but also with male gender. Ponce-Rojo et al. (2013) also consider the gender variable a significant factor in internet addiction, and their results again suggest that male students are more affected by internet addiction than female students are. In this regard, Tsitsika et al. (2014) examined seven European countries (Greece, Spain, Poland, Germany, Romania, the Netherlands, and Iceland) and found that the prevalence of dysfunctional internet behaviour was significantly higher among male adolescents than among their female counterparts. Durkee et al. (2012) also confirmed that pathological internet use correlates significantly with male gender in a sample of countries such as Austria, Estonia, France, Germany, Hungary, Ireland, Israel, Italy, Romania, Slovenia, Spain, and Sweden. Thus, there are many international studies confirming the fact that internet addiction varies by gender, and this disorder is more prevalent in male students (Chaudhari et al., 2015; Sayyah \& Khanafereh, 2019). On the other hand, there are studies that do not confirm the predominance of males in internet addiction to such a clear extent as in the above-mentioned studies. In their Croatian study, Cernja et al. (2019) found gender differences in the IAT sub-scales among students aged between 15 and 20, and the findings showed higher scores of social problems in males, while females had higher scores in the sub-scale which represents the items related to neglecting work and lack of self-control. The fact that internet addiction is not just a matter of male dominance was proved by the results of Leung (2004), who confirmed that female students tend to be more addicted than male students. Furthermore, in European countries such as Poland, Slovenia, Estonia, and France, women were more vulnerable to internet addiction than men (Su et al., 2019). In contrast, the fact that there were no differences in the total IAT score between male and female students was confirmed by Khan et al. (2017). In the Slovak Republic, Orosová et al. (2014) did not find a significant effect of gender on generalized problematic internet use either. This discrepancy in the results of the studies can be explained by the findings revealed by Su et al. (2019), who confirmed that economic factors, internet availability, and social norms may be related to gender differences in internet addiction tendencies across countries. The authors also found that the effect of gender is smaller in countries with higher per capita GDP and higher internet penetration.

In their conclusion, many authors point to the urgent need to prevent internet addiction among different groups of the population, but especially young people; therefore, research on this issue can help implement effective interventions not only through public policies, but also through the approach of parents and educators, who shape the environment in which the individual develops (Vondrackova \& Gabrhelik, 2016). On the evidence of the above-mentioned findings, it can be stated that research in this issue is more than welcome. Accordingly, the present study is devoted to the assessment of gender differences in internet addiction among university students. The purpose of this study is to provide information about the current situation in the Slovak Republic.

\section{METHODOLOGY}

With an emphasis on the above-mentioned findings in the previous section, which provide essential information about gender differences in internet addiction, the primary objective of the study was to assess the differences in internet addiction between males and females in a sample of university students in the Slovak Republic. This objective was achieved on the basis of several analytical processes, including the application of descriptive statistics and the testing of differences in internet addiction between males and females in general, as well as for individual sub-scales.

A questionnaire survey was conducted in 2020. Data collection was performed on a sample of Slovak university students by a combination of selection based on quota selection. After irrelevant observations had been removed, the research sample consisted of 1612 observations (261 observations were removed because of their irrelevance). In terms of selection, the intention of the research was to include a sufficient number of all fields of study as well as all universities in the Slovak Republic (a very significant part was achieved - about 80\%). The relevance of the observations was determined on the basis of the verification of the questionnaire items (verification item - a statement that one million has six zeros (a numerical expression was also given); exclusion items, obviously incorrectly answered items conflicting opinions). In terms of the degree the students were studying for, the research sample represented the observations of students studying for their first degree (68.2\%), students studying for their second degree (25.6\%), students studying for their combined first and second degrees (2.4\%), and students studying for their third degree (3.8\%). Regarding their place of residence, $49.3 \%$ of the students were from the countryside, $11.6 \%$ from towns with up to 10,000 inhabitants, $31.5 \%$ from cities with 10,001-100,000 inhabitants, and 7.7\% from cities with 100,001-1,000,000 inhabitants. From the point of view of gender, males accounted for $36.2 \%$ of the observations in the research sample and females for $63.8 \%$.

The internet addiction scale consisted of several sub-scales defined on the basis of the standardized Internet Addiction Test (IAT) methodology, in which "Salience" is represented by five items (theoretical interval 0-25), "Excessive Use" also by five items (theoretical interval 0-25), "Neglect Work" by three items (theoretical interval 0-15), "Anticipation" by two items (theoretical interval 0-10), "Lack of Control" by three items (theoretical interval 0-15), and "Neglect Social Life" by two items (theoretical interval 0-10), and thus the IAT as a whole represents the sum of all the items that are included (Young, 2017).

The fulfilment of the above-mentioned objective required the application of several analytical processes, namely descriptive analysis (arithmetic mean (Mean), median (Median), standard deviation (Std. Dev.), minimum (Min), maximum (Max), interquartile range (IQR), skewness (Skewness), and kurtosis (Kurtosis)), as well as analysis of differences (Wilcoxon W). Box plots were used to visualize the results. The IBM SPSS statistics statistical software v. 26 (Armonk, New York, United States) was used for the analysis. 
Table 1 | Descriptive statistics

\begin{tabular}{|c|c|c|c|c|c|c|c|}
\hline Statistic & Salience & $\begin{array}{c}\text { Excessive } \\
\text { Use }\end{array}$ & $\begin{array}{c}\text { Neglect } \\
\text { Work }\end{array}$ & Anticipation & $\begin{array}{l}\text { Lack of } \\
\text { Control }\end{array}$ & $\begin{array}{c}\text { Neglect } \\
\text { Social Life }\end{array}$ & IAT \\
\hline Mean & 4.69 & 6.92 & 5.00 & 3.34 & 4.48 & 1.58 & 26.01 \\
\hline Median & 4 & 6 & 5 & 3 & 4 & 1 & 24 \\
\hline Std. Dev. & 3.90 & 3.84 & 2.83 & 1.84 & 3.05 & 1.38 & 13.41 \\
\hline Min & 0 & 0 & 0 & 0 & 0 & 0 & 0 \\
\hline Max & 25 & 23 & 15 & 10 & 15 & 10 & 90 \\
\hline IQR & 5 & 5 & 4 & 3 & 4 & 1 & 18 \\
\hline Skewness & 1.11 & 0.63 & 0.58 & 0.46 & 0.65 & 1.31 & 0.75 \\
\hline Kurtosis & 1.35 & 0.22 & 0.12 & 0.15 & -0.03 & 2.52 & 0.69 \\
\hline \multicolumn{8}{|l|}{ MALES } \\
\hline Mean & 5.50 & 7.41 & 5.39 & 3.38 & 4.57 & 1.92 & 28.16 \\
\hline Median & 5 & 7 & 5 & 3 & 4 & 2 & 27 \\
\hline Std. Dev. & 4.14 & 4.07 & 2.92 & 1.92 & 3.10 & 1.46 & 14.08 \\
\hline Min & 0 & 0 & 0 & 0 & 0 & 0 & 2 \\
\hline Max & 25 & 23 & 15 & 10 & 14 & 7 & 90 \\
\hline IQR & 6 & 5 & 4 & 3 & 5 & 2 & 18 \\
\hline Skewness & 1.00 & 0.63 & 0.56 & 0.55 & 0.70 & 1.00 & 0.80 \\
\hline Kurtosis & 1.31 & 0.40 & 0.14 & 0.34 & 0.06 & 0.91 & 0.95 \\
\hline \multicolumn{8}{|l|}{ FEMALES } \\
\hline Mean & 4.23 & 6.64 & 4.77 & 3.32 & 4.43 & 1.39 & 24.79 \\
\hline Median & 4 & 6 & 4 & 3 & 4 & 1 & 23 \\
\hline Std. Dev. & 3.68 & 3.67 & 2.76 & 1.79 & 3.01 & 1.30 & 12.87 \\
\hline Min & 0 & 0 & 0 & 0 & 0 & 0 & 0 \\
\hline Max & 20 & 19 & 15 & 10 & 15 & 10 & 85 \\
\hline IQR & 5 & 5 & 4 & 3 & 4 & 1 & 18 \\
\hline Skewness & 1.16 & 0.59 & 0.57 & 0.39 & 0.63 & 1.55 & 0.68 \\
\hline Kurtosis & 1.27 & -0.07 & 0.07 & -0.03 & -0.10 & 4.25 & 0.33 \\
\hline
\end{tabular}

\section{RESULTS}

The following text and calculations represent the processes leading to the fulfilment of the main objective. The whole section devoted to analyses and results is divided into two successive parts. The first part presents the basic outputs of the descriptive analysis, and the second part is devoted to testing gender differences in the analysed constructs of addictive behaviour on the internet.

The essence of the descriptive statistics presented in Table 1 is to define and characterize more clearly the structure of the variables entering the analyses. As mentioned in the methodological section, the individual IAT sub-scales could not be compared with each other, as these sub-scales consisted of the sums of different numbers of items. The gender comparison of outputs makes the most sense in this case. When interpreting the mean values, it is necessary to keep in mind that the higher the value of the output, the greater the intensity of the internet addiction. In the comparison of males and females, the variability represented by the standard deviation acquires lower values in the case of females, and thus their responses were more consistent, i.e. the responses of the females differed less from each other, as confirmed by the IQR value. Skewness and Kurtosis values outside the range of -1 to 1 indicate some deviations from the normal statistical distribution.

Table 2 provides the outputs of internet addiction testing between gender categories. On the basis of the outputs of the p-value $(<0.001)$, a significant difference (inequality) between males and females can be confirmed. Figure 1 shows the direction of this difference.

Table 2 | Gender differences in internet addiction

\begin{tabular}{lc}
\hline Test Statistics & IAT \\
\hline Wilcoxon W & 787483.50 \\
Sig. & $<0.001$ \\
\hline
\end{tabular}

As expected from the outputs of the descriptive analysis, the box plots show a higher rate of internet addiction for the males than for the females. The following part of the study deals with the analysis of the individual sub-scales of internet addiction. 
Figure 1 | Box plots - gender differences in internet addiction

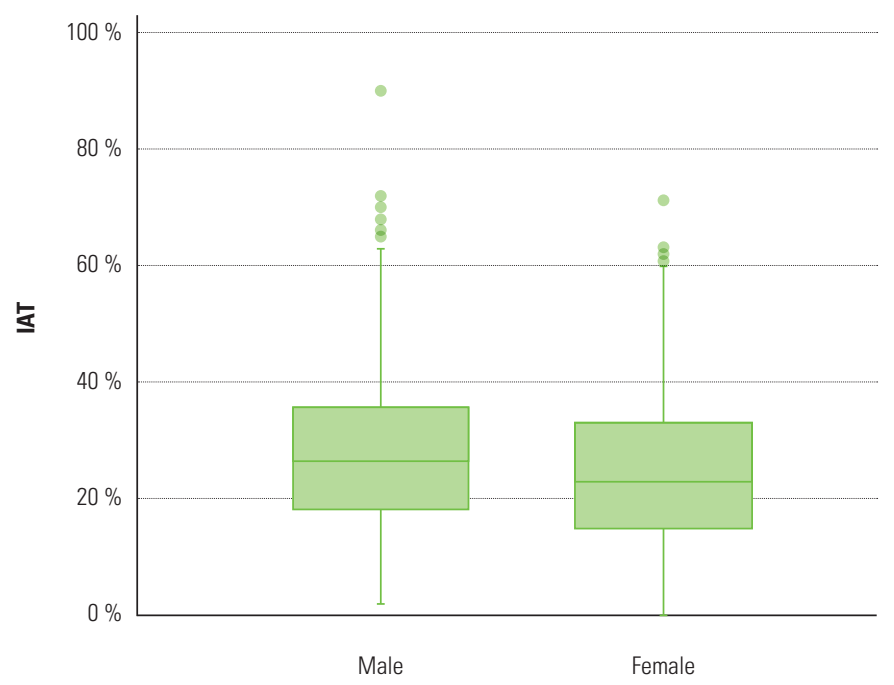

Figure 2 | Box plots - gender differences in sub-scales of internet addiction
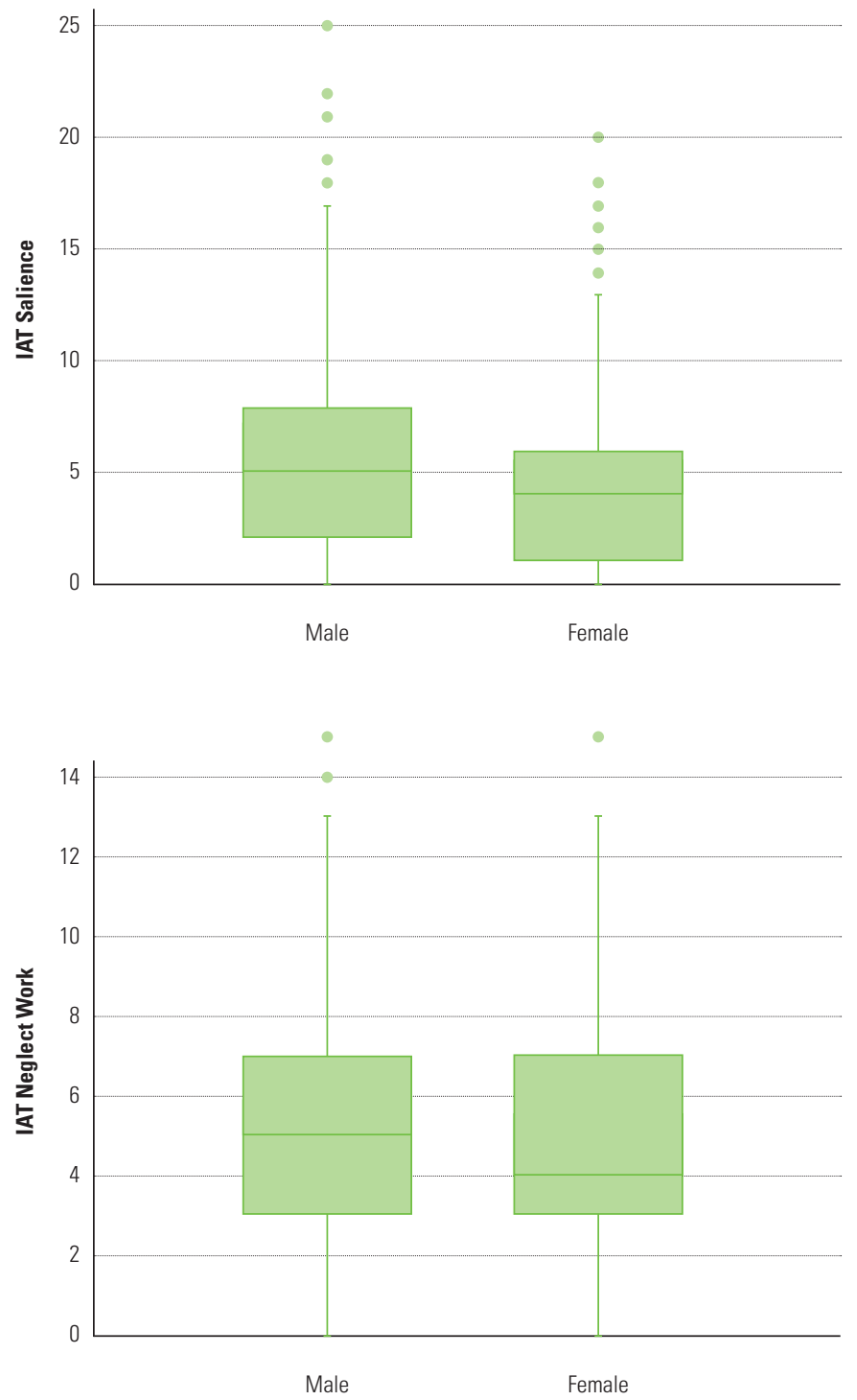

When interpreting the output of the difference analysis presented in Table 3, it is necessary to focus on the "Sig." column, which shows the asymptotic significance, i.e. the p-value. Values higher than 0.05 were found only in two cases ( $p$-value: Anticipation $=0.775$; Lack of Control = 0.501). In the other four cases, it is possible to speak of a demonstrable difference (inequality) between males and females.

Table 3 showed significant differences in the four cases of the IAT sub-scales; these cases are shown in Figure 2. On the evidence of the outputs, the male students showed a higher intensity of internet addiction. Of these cases, the greatest difference was found in the Neglect Social Life sub-scale. In addition to outliers (small circle), the Neglect Social Life box plot also shows extreme values marked with a star.
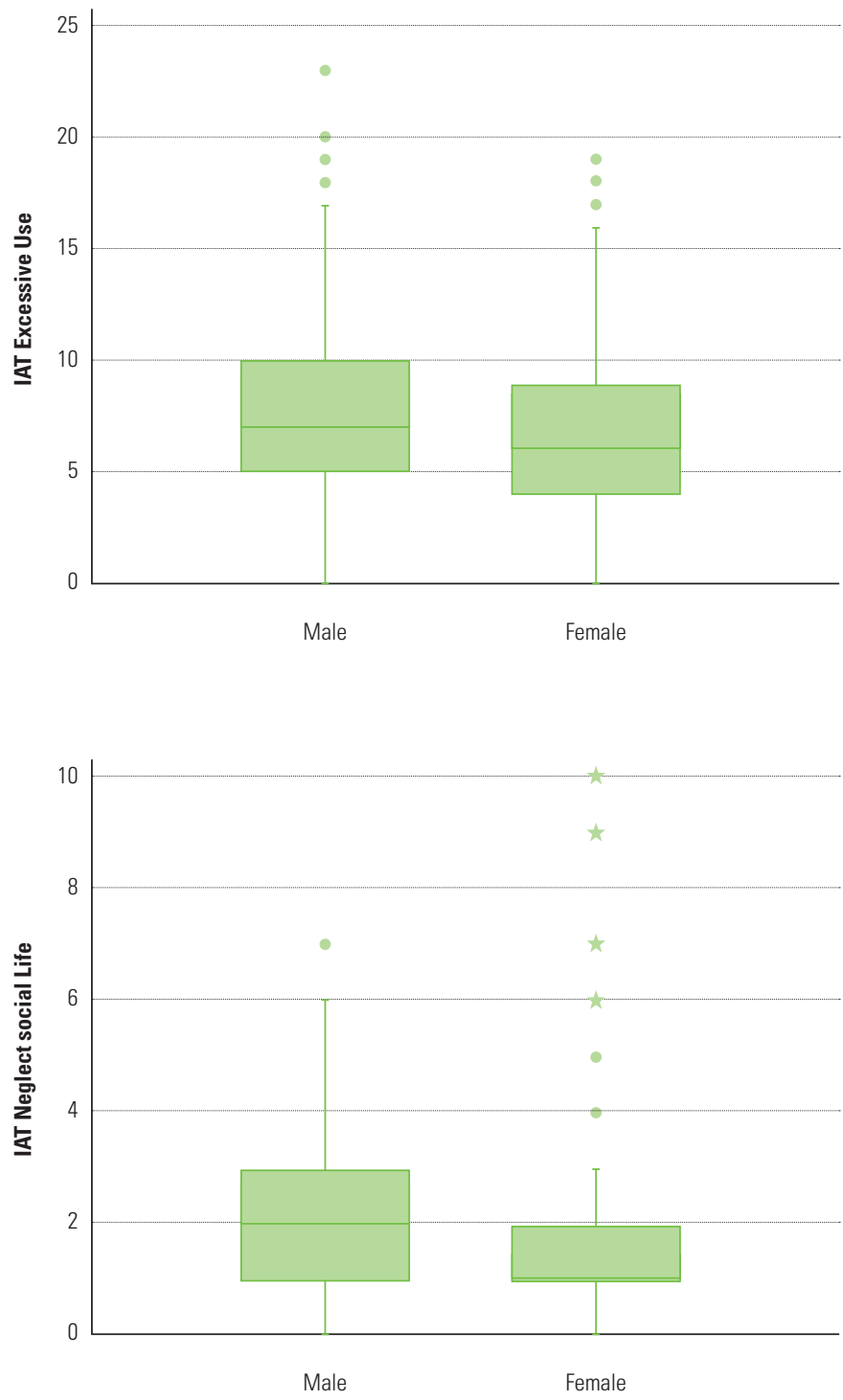
Table 3 | Gender differences in sub-scales of internet addiction

\begin{tabular}{lcc}
\hline Sub-scale IAT & Wilcoxon W & Sig. \\
\hline Salience & 771318 & 0.000 \\
Excessive Use & 796577 & 0.000 \\
Neglect Work & 792986 & 0.000 \\
Anticipation & 826551 & 0.775 \\
Lack of Control & 823072 & 0.501 \\
Neglect Social Life & 762608 & 0.000 \\
\hline
\end{tabular}

\section{DISCUSSION AND CONCLUSION}

Internet addiction is a modern phenomenon, caused mainly by globalization, technological progress, and the development of innovations. Young people represent a group that is at particular risk because of this phenomenon and its consequences (Echeburua \& de Corral, 2010). It should also be noted that no significant changes in the limitations of information and communication technologies are expected in the future; on the contrary, there is a presumption of their expansion. Similarly, there may be concerns about an increase in behavioural disorders associated with internet addiction. In this context, the risks to physical health (Flisher, 2010; Nazik \& Gunes, 2019) and mental health (Cerniglia et al., 2017; Tural Hesapcioglu \& Yesilova, 2020) should not be forgotten. For this reason, internet addiction in high-risk population groups should be systematically monitored. The lifestyle of university students can be a predictor of this addiction, which may be a serious problem in the future. Therefore, the present study focuses on this population group.

The main objective of the study was to assess the differences in internet addiction between males and females in a sample of university students in the Slovak Republic. A further purpose of the research was to assess these differences in general terms as well as in the specific constructs of internet addiction in order to provide information about the current situation in the Slovak Republic.

Using basic descriptive analysis, it was found that the mean values of the results generally indicate acceptable outputs, as the rate of intensity of internet addiction is not alarming. On the other hand, it would not be sensible to ignore this health problem and pretend that there is no internet addiction among students. Higher scores were found for three sub-scales of the IAT, namely Neglect Work, Anticipation, and Lack of Control. The results also show that the male students generally had higher internet addiction scores than the female students. A statistically significant difference between males and females in the total IAT rate was confirmed and it can be concluded that the male students showed a higher rate of internet addiction. These results are consistent with some of the previous research conducted by Canan et al. (2012), Chaudhari et al. (2015), Omoyemiju and Popoola (2020), Ponce-Rojo et al. (2013), Sayyah and Khanafereh (2019), and Shao et al. (2018). However, this fact has not been confirmed in every similar study and there is evidence of female dominance in internet addiction (Leung, 2004). Additionally, Khan et al. (2017) did not confirm any gender differences in the total IAT score in their study. These discrepancies may be related to economic factors, internet availability, and social norms in countries ( $\mathrm{Su}$ et al., 2019). When the individual sub-scales of the IAT were assessed, significant differences were found for Salience, Excessive Use, Neglect Work, and Neglect Social Life. Again, it can be stated that in the case of the individual sub-scales too, the male students showed a significantly higher degree of internet addiction. On the other hand, there was no difference for Anticipation and Lack of Control. These findings can be compared with the findings of Cernja et al. (2019), who also confirmed gender differences for the IAT subscales, but in their results, the females showed higher scores on the variables related to neglecting work and lack of self-control.

Information on non-substance types of addiction, especially internet addiction, is hardly distributed at all among university students. This lack of information can be perceived very negatively, especially with an emphasis on the possible threat of internet addiction. In some cases, addicted people are aware of their problem, but do not have the courage to talk about it in person. In this case, the internet can also be useful, as it can offer a lot of space for content which should focus on help and support for internet addicts. Creating such content is very important, because this form is the one that is closest to addicts. Helpdesks, non-profit organizations, and professionals who can provide guidance on how to tackle this issue in people's lives should also be fully promoted on the internet. Of course, these non-profit organizations and prevention and education should be properly supported by the state. At the same time, efforts in this area of internet addiction should be more oriented towards men.

Potential limitations include the fact that the data was obtained during the SARS-CoV-2 pandemic. Nevertheless, the research sample can be considered representative and valid. Future research will focus on proving differences in terms of other socio-economic characteristics. It is also planned to examine this issue among other groups of the population, not only among university students. 
Acknowledgments: We thank the university students, without whom the research would not be possible. We would also like to thank the university representatives and scientific, pedagogical, and administrative workers, who were very helpful in distributing the questionnaire.

Authors' contributions: Conceptualisation: Silvia Megyesiová; Data curation: Martin Rigelský and Viera Ivanková; Methodology: Martin Rigelský; Formal analysis: Martin Rigelský; Results: Viera Ivanková; Visualisation: Jaroslav Šejvl and Ihsan Al Khouri; Final edition: Martin Rigelský, Silvia Megyesiová and Viera Ivanková. All authors have read and agreed to the published version of the manuscript.
Declaration of interest: Authors declare that they do not have any competing financial, professional, or personal interests from other parties.

\section{REFERENCES}

Aznar-Diaz, I., Romero-Rodriguez, J. M., Garcia-Gonzalez, A., \& RamirezMontoya, M. S. (2020). Mexican and Spanish university students' internet addiction and academic procrastination: Correlation and potential factors. Plos One, 15(5), e0233655. https://doi.org/10.1371/journal.pone.0233655

Berner, J. E., Santander, J., Contreras, A. M., \& Gomez, T. (2014). Description of internet addiction among Chilean medical students: A cross-sectional study. Academic Psychiatry, 38(1), 11-14. https://doi.org/10.1007/s40596-013-0022-6

Canan, F., Ataoglu, A., Ozcetin, A., \& Icmeli, C. (2012). The association between internet addiction and dissociation among Turkish college students. Comprehensive Psychiatry, 53(5), 422-426. https://doi.org/10.1016/j.comppsych.2011.08.006

Cerniglia, L., Zoratto, F., Cimino, S., Laviola, G., Ammaniti, M., \& Adriani, W. (2017). Internet addiction in adolescence: Neurobiological, psychosocial and clinical issues. Neuroscience \& Biobehavioral Reviews, 76, 174-184. https://doi.org/10.1016/..neubiorev.2016.12.024

Cernja, I., Vejmelka, L., \& Rajter, M. (2019). Internet addiction test: Croatian preliminary study. BMC Psychiatry, 19(1), 388. https://doi.org/10.1186/s12888-019-2366-2

Chang, M. K., \& Law, S. P. M. (2008). Factor structure for Young's Internet Addiction Test: A confirmatory study. Computers in Human Behavior, 24(6), 2597-2619. https://doi.org/10.1016/j.chb.2008.03.001

Chaudhari, B., Menon, P., Saldanha, D., Tewari, A., \& Bhattacharya, L. (2015). Internet addiction and its determinants among medical students. Industrial Psychiatry Journal, 24(2), 158-162. https://doi.org/10.4103/0972-6748.181729

Chen, Y. F., \& Peng, S. S. (2008). University students' internet use and its relationships with academic performance, interpersonal relationships, psychosocial adjustment, and self-evaluation. Cyberpsychology \& Behavior, 11(4), 467-469. https://doi.org/10.1089/cpb.2007.0128

Chi, X., Lin, L., \& Zhang, P. (2016). Internet addiction among college students in China: Prevalence and psychosocial correlates. Cyberpsychology Behavior and Social Networking, 19(9), 567-573. https://doi.org/10.1089/cyber.2016.0234

Christakis, D. A., Moreno, M. M., Jelenchick, L., Myaing, M. T., \& Zhou, C. (2011). Problematic internet usage in US college students: A pilot study. BMC Medicine, 9, 77. https://doi.org/10.1186/1741-7015-9-77

Durkee, T., Kaess, M., Carli, V., Parzer, P., Wasserman, C., Floderus, B., Apter, A., Balazs, J., Barzilay, S., Bobes, J., Brunner, R., Corcoran, P., Cosman, D., Cotter, P., Despalins, R., Graber, N., Guillemin, F., Haring, C., Kahn, J. P., ... Wasserman, D. (2012). Prevalence of pathological internet use among adolescents in Europe: Demographic and social factors. Addiction, 107(12), 2210-2222. https://doi.org/10.1111/j.1360-0443.2012.03946.x

Echeburua, E., \& de Corral, P. (2010). Addiction to new technologies and to online social networking in young people: A new challenge. Adicciones, 22(2), 91-95. https://doi.org/10.20882/adicciones.196
Flisher, C. (2010). Getting plugged in: An overview of internet addiction. Journal of Paediatrics and Child Health, 46(10), 557-559. https://doi.org/10.1111/j.1440-1754.2010.01879.x

Guan, S. S. A., \& Subrahmanyam, K. (2009). Youth Internet use: Risks and opportunities. Current Opinion in Psychiatry, 22(4), 351-356. https://doi.org/10.1097/YC0.0b013e32832bd7e0

Javaeed, A., Jeelani, R., Gulab, S., \& Ghauri, S. K. (2020). Relationship between internet addiction and academic performance of undergraduate medical students of Azad Kashmir. Pakistan Journal of Medical Sciences, 36(2), 229-233. https://doi.org/10.12669/pjms.36.2.1061

Khan, M. A., Shabbir, F., \& Rajput, T. A. (2017). Effect of gender and physical activity on internet addiction in medical students. Pakistan Journal of Medical Sciences, 33(1), 191-194. https://doi.org/10.12669/pjms.331.11222

Leung L. (2004). Net-generation attributes and seductive properties of the internet as predictors of online activities and internet addiction. Cyberpsychology \& Behavior, 7(3), 333-348. https://doi.org/10.1089/1094931041291303

Levy, J. A., \& Strombeck, R. (2002). Health benefits and risks of the internet. Journal of Medical Systems, 26(6), 495-510. https://doi.org/10.1023/A:1020288508362

Li, W., O'Brien, J. E., Snyder, S. M., \& Howard, M. 0. (2015). Characteristics of internet addiction/pathological internet use in US university students: A qualitative-method investigation. Plos One, 10(2), e0117372. https://doi.org/10.1371/journal.pone.0117372

Lu, X., Yeo, K. J., Guo, F., \& Zhao, Z. (2020). Factor structure and a multiple indicators multiple cause model of internet addiction test: The effect of sociodemographic and internet use variables. Current Psychology, 39(3), 769-781. https://doi.org/10.1007/s12144-019-00234-9

Masi, G., Berloffa, S., Muratori, P., Paciello, M., Rossi, M., \& Milone, A. (2020). Internet addiction disorder in referred adolescents: A clinical study on comorbidity. Addiction Research \& Theory. https://doi.org/10.1080/16066359.2020.1772242

Nazik, F., \& Gunes, G. (2019). Problematic internet usage and healthy lifestyle behaviors in university students. Cukurova Medical Journal, 44, 41-48. https://doi.org/10.17826/cumj.533376

Omoyemiju, M. A., \& Popoola, B. I. (2020). Prevalence of internet addiction among students of Obafemi Awolowo University, Ile-Ife, Nigeria. British Journal of Guidance \& Counselling. https://doi.org/10.1080/03069885.2020.1729339

Ooi, C. Y., Mooi, C. S., Ali, N., Sidek, S. K. H., Amat, A., Yatim, Y., Yahaya, Z., Shamsuddin, N., Ibrahim, I., Majid, F. A., Othman, F. S., Zakaria, N. S., Abidin, A., \& Talib, N. H. (2020). Prevalence and factors associated with internet addiction among adolescents in Malaysia: A cross-sectional study. Journal of Indian Association for Child and Adolescent Mental Health, 16(2), 33-44. 
Orosová, O., Benka, J., Sebena, R., \& Gajdošová, B. (2014). Gender, optimism, perceived stress on problematic internet use among Slovak university students. In C. Pracana (Ed.), Psychology Applications \& Developments (306-315). inScience Press.

Ponce-Rojo, A., Hernandez-Vega, L., Fernandez-Rodriguez, J., HernandezContreras, J., Moreno-Badajos, P., Magana-Lopez, Y., Sanchez-Medina, E., \& Castaneda-Barajas, A. (2013). Gender differences in freshmen internet addicts in the second largest public university in Mexico. Proceedings Paper of 6th International Conference on Education, Research and Innovation (ICERI), 7088-7096.

Sayyah, M., \& Khanafereh, S. (2019). Prevalence of internet addiction among medical students: A study from southwestern Iran. Central European Journal of Public Health, 27(4), 326-329. https://doi.org/10.21101/cejph.a5171

Shao, Y. J., Zheng, T., Wang, Y. Q., Liu, L., Chen, Y., \& Yao, Y. S. (2018). Internet addiction detection rate among college students in the People's Republic of China: A meta-analysis. Child and Adolescent Psychiatry and Mental Health, 12, 25. https://doi.org/10.1186/s13034-018-0231-6

Shaw, M., \& Black, D. W. (2008). Internet addiction: Definition, assessment, epidemiology and clinical management. CNS Drugs, 22(5), 353-365 https://doi.org/10.2165/00023210-200822050-00001

Su, W., Han, X., Jin, C., Yan, Y., \& Potenza, M. N. (2019). Are males more likely to be addicted to the internet than females? A meta-analysis involving 34 global jurisdictions. Computers in Human Behavior, 99, 86-100.

https://doi.org/10.1016/j.chb.2019.04.021

Travaglino, G. A., Li, Z., Zhang, X., Lu, X., \& Choi, H. S. (2020). We are all in this together: The role of individuals' social identities in problematic engagement with video games and the internet. British Journal of Social Psychology, 59(2), 522-548. https://doi.org/10.1111/bjso.12365

Tsimtsiou, Z., Haidich, A. B., Spachos, D., Kokkali, S., Bamidis, P., Dardavesis, T., \& Arvanitidou, M. (2015). Internet addiction in Greek medical students: An online survey. Academic Psychiatry, 39(3), 300-304. https://doi.org/10.1007/s40596-014-0273-x

Tsitsika, A., Janikian, M., Schoenmakers, T. M., Tzavela, E. C., Olafsson, K., Wojcik, S., Macarie, G. F., Tzavara, C., \& Richardson, C. (2014). Internet addictive behavior in adolescence: A cross-sectional study in seven European countries. Cyberpsychology Behavior and Social Networking, 17(8), 528-535. http://doi.org/10.1089/cyber.2013.0382

Tural Hesapcioglu, S., \& Yesilova, H. (2020). Internet addiction prevalence in youths and its relation with depressive symptoms, self-esteem, and bullying. Anadolu Psikiyatri Dergisi-Anatolian Journal of Psychiatry, 21(5), 483-490. https://doi.org/10.5455/apd.72881

Vega-Almeida, R. L., \& Arencibia-Jorge, R. (2019). The dark side of internet: A bibliometric study of online addictive behaviors. Revista Espanola de Documentacion Cientifica, 42(4), e251. https://doi.org/10.3989/redc.2019.4.S8

Vondrackova, P., \& Gabrhelik, R. (2016). Prevention of internet addiction: A systematic review. Journal of Behavioral Addictions, 5(4), 568-579. https://doi.org/10.1556/2006.5.2016.085

Young, K. S. (2017). Internet Addiction Test (IAT). Stoelting. 